\title{
PERAN INTRAPRENEURSHIP DALAM MEMBANGUN DAYA SAING KULTURAL DI PERGURUAN TINGGI: SEBUAH KERANGKA PENELITIAN
}

\author{
Agustinus Dedy Handrimurtjahjo \\ Jurusan Manajemen, Fakultas Ekonomi dan Komunikasi, BINUS University \\ Jln. K.H. Syahdan No. 9, Palmerah, Jakarta Barat 11480 \\ ahandrimurtjahjo@binus.ac.id
}

\begin{abstract}
This paper develops a conceptual framework for intended study which will examine the role of intrepreneurship in building cultural competitiveness in Higher Education (HE). Intrapreneurship (entrepreneurship within existing organizations) is used on organizational level. Previous study argued that four variables of Cultural Competitiveness (entrepreneurship, innovativeness, market orientation, and organizational learning) had a direct effect on organizational performance. Meanwhile, the other study argued that Intrapreneurship had a direct effect on organizational performance. The effect of the four market-based elements (intrapreneurship, market orientation, innovativeness and organizational learning) on performance will be examined by testing two alternative analytical models in different types of higher education institutions. The size and age of HE institutions are also considered as the interactive elements that might be different across different $H E$ institutions. Testing two alternative models in developing countries will support whether the generalizability of the two alternative models and the constructs used in different country setting is acceptable.
\end{abstract}

Keywords: intrapreneurship, cultural competitiveness, higher education, market orientation, innovativeness, organizational learning

\begin{abstract}
ABSTRAK
Makalah ini mengembangkan sebuah kerangka kerja konseptual untuk studi terencana yang akan menguji peran interpreneurship dalam membangun daya saing budaya di Pendidikan Tinggi (PT). Intrapreneurship (kewirausahaan dalam organisasi yang sudah ada) digunakan pada tingkat organisasi. Penelitian sebelumnya berpendapat bahwa empat variabel Daya Saing Budaya (kewirausahaan, inovasi, orientasi pasar, dan pembelajaran organisasional) memiliki efek langsung pada kinerja organisasi. Pengaruh empat elemen berbasis pasar (intrapreneurship, orientasi pasar, inovasi dan pembelajaran organisasi) terhadap kinerja akan dikaji dengan menguji dua model analisis alternatif di berbagai jenis institusi perguruan tinggi. Ukuran dan usia institusi PT juga dianggap sebagai elemen interaktif yang mungkin berbeda di berbagai instansi PT. Pengujian dua model alternatif di negara berkembang akan mendukung apakah generalisasi dari dua model alternatif dan konstruksi yang digunakan dalam pengaturan negara yang berbeda dapat berterima.
\end{abstract}

Kata kunci: intrapreneurship, daya saing budaya, perguruan tinggi, orientasi pasar, inovasi, pembelajaran organisasi 


\section{PENDAHULUAN}

Meningkatnya persaingan perguruan tinggi di Indonesia menuntut perubahan internal bagi setiap organisasi dalam menyiapkan strategi bersaing agar tetap bertahan dalam lingkungan yang penuh ketidakpastian. Berdasarkan data dari Direktori PT Dikti Kemendiknas (per 11 September 2009), tercatat sebanyak 2963 perguruan tinggi yang terdiri dari 83 Perguruan Tinggi Negeri (PTN) dan 2880 Perguruan Tinggi Swasta (PTS). Meskipun lembaga perguruan tinggi mudah untuk masuk ke pasar, jumlah PTS cenderung menurun karena intensitas persaingan dan adanya penggabungan (merger). Konsekuensinya, baik PTN maupun PTS harus menawarkan berbagai program untuk menciptakan pendapatan (revenue) setinggi mungkin terhadap peluang pasar yang ada. Perguruan Tinggi Negeri (PTN) saat ini semakin proaktif dan progresif dalam menawarkan produk-produk pendidikan karena mereka harus bebas secara finansial tanpa mengandalkan lagi subsidi dari pemerintah. Baik PTN maupun PTS saat ini aktif melakukan praktik pemasaran yang dinamis untuk menarik minat calon mahasiswa dibandingkan tahun-tahun sebelumnya.

Dalam ekonomi transisi, negara berkembang bergerak menuju ke arah ekonomi maju; pertumbuhan biasanya menjadi tujuan utama. Hal ini terjadi pula dalam industri perguruan tinggi. Pertumbuhan dan kemampuan bertahan telah menjadi tujuan yang paling umum. Oleh karenanya, sangat penting untuk menerapkan teori manajemen strategi pada perguruan tinggi karena hal ini memberikan beberapa pandangan yang berbeda pada penentuan keberhasilan ekonomi seperti Pandangan Berbasis Sumber Daya (Resource-Based View) dan Pendekatan Kekuatan Persaingan (Competitive Forces Approach). Saat ini diyakini bahwa aset tak berwujud (intangible assets) adalah dasar dalam menentukan kemampuan unggul suatu perusahaan yang telah mendorong para ahli menggunakan konsep RBV untuk menjelaskan dan menganalisis penentu utama daya saing kultural sesuai dengan jenis organisasi seperti usia dan ukuran perguruan tinggi.

Dengan menggabungkan konsep RBV, perusahaan dan organisasi yang digerakkan pasar (market driven organization), Hult, Snow, dan Kandemir (2003) menyatakan bahwa empat komponen berbasis pasar: entrepreneurship, innovatiness, market orientation dan organizational learning secara bersama-sama meningkatkan daya saing kulural perusahaan (cultural competitiveness). Istilah intrapreneurship (kewirausahaan dalam organisasi) digunakan sebagai studi pada tingkat organisasi. Daya saing kultural adalah tingkat dimana organisasi cenderung menemukan dan mengisi kesenjangan antara apa yang diinginkan oleh pasar dan apa yang ditawarkan oleh pasar saat ini (Hult, Snow, dan Kandemir, 2003). Dalam kerangka daya saing kultural, Hult, Snow, dan Kandemir (2003) menemukan dampak entrepreneurship sebagai salah satu dari empat komponen berbasis pasar yang berlaku pada jenis organisasi yang berbeda.

Hult, Snow, dan Kandemir (2003) menambahkan bahwa entrepreneurship menggambarkan fenomena yang paling berpengaruh dan proaktif dalam kerangka daya saing kultural yang membuatnya menjadi penting untuk diketahui perannya dalam organisasi. Bagaimanapun juga, peran entrepreneurship perlu dilengkapi dalam dua cara utama, yaitu: pertama, tergantung pada kondisi tertentu, beberapa organisasi membutuhkan lebih kapabilitas kewirausahaan. Kedua, organisasi yang ingin menjadi highly entrepreneurial harus mengembangkan budaya kewirausahaan yang meliputi faktor-faktor seperti kemampuan belajar dan fokus pada pasar (Hult, Snow, dan Kandemir, 2003). Maka, kinerja unggul organisasi kemungkinan besar dihasilkan dari kesesuaian antara faktor daya saing budaya tertentu dengan jenis organisasi spesifik (Miles \& Snow, dalam Hult, Snow, dan Kandemir, 2003). Sejauh ini banyak riset empiris dan penilaian studi telah dibuat untuk mengkaji konsep RBV terutama dalam negara maju seperti yang dilakukan oleh Hult, Snow, dan Kandemir tahun 2003. Akan tetapi, hanya ada sedikit studi komprehensif yang dilakukan dalam negara transisi seperti Indonesia untuk menguji penentu utama hasil organisasi sesuai dengan teori RBV. Dengan melihat kegunaan penentu utama kesuksesan organisasi, penelitian ini akan menguji peran intrapreneurship dalam membangun daya saing kultural perguruan tinggi di Indonesia. 
Intrapreneurship dipilih sebagai fenomena yang paling berpengaruh dan proaktif terhadap daya saing kulutral (Hult, Snow, dan Kandemir, 2003). Peran intrapreneurship dalam perguruan tinggi juga penting karena karakteristik yang dinamis dalam industri ini. Terbukti dengan beberapa perguruan tinggi yang bangkrut dan beberapa yang melakukan merger karena daya saing kultural mampu dalam menemukan dan mengisi kesenjangan antara apa yang diinginkan pasar dan apa yang ditawarkan pasar saat ini (Hult, Snow, dan Kandemir, 2003). Dikatakan bahwa empat komponen berbasis pasar dalam kerangka daya saing kulutral memberikan beberapa model yang dapat diterapkan pada berbagai jenis lembaga perguruan tinggi. Penemuan model terbaik yang sesuai dengan jenis organisasi akan mengarahkan fokus yang lebih baik pada penentu utama yang akan menyumbangkan pada keunggulan organisasi.

Penelitian ini dilakukan untuk menemukan jawaban terhadap permasalahan, yaitu: (1) bagaimanakah peran intrapreneurship dalam membangun daya saing kultural pada lembaga perguruan tinggi di Indonesia; dan (2) apakah terdapat perbedaan peran intrapreneurship dalam membangun daya saing kultural pada lembaga perguruan tinggi di Indonesia berdasarkan usia dan ukuran organisasi.

Tujuan penelitian ini adalah: (1) untuk mengetahui peran intrapreneurship dalam membangun daya saing kultural pada lembaga perguruan tinggi di Indonesia; dan (2) untuk mengetahui perbedaan peran intrapreneurship dalam membangun daya saing kultural pada lembaga perguruan tinggi di Indonesia berdasarkan usia dan ukuran organisasi.

\section{Konsep Entrepreneurship}

Entrepreneurship seperti yang diungkapkan oleh Schumpeter merupakan hal yang penting dalam pembangunan ekonomi (Hult, Snow, dan Kandemir, 2003). Schumpeter membuat perbedaan antara entrepreneurship sebagai fungsi dan entrepreneur sebagai orang. Seorang entrepreneur dapat menjadi seseorang yang menciptakan inovasi, pengusaha mandiri, seorang karyawan atau manajer perusahaan dan lain-lain. Lebih lanjut, serangkaian inovasi diciptakan oleh entrepreneur tak terbatas secara virtual, meliputi pengembangan produk/jasa baru, saluran distribusi baru atau reorganisasi industri keseluruhan (Birkinshaw, dalam Hult, Snow, dan Kandemir, 2003). Entrepreneurship sebagai fungsi merujuk pada gangguan keseimbangan dalam perusahaan (atau ekonomi) yang disebabkan oleh penciptaan dan aplikasi kombinasi baru sumber daya. Tingkatan entrepreneurship juga bervariasi dalam lintas organisasi. Sebagai contoh, perusahaan yang mengejar strategi prospector, rata-rata lebih mengombinasikan sumber daya dibandingkan perusahaan yang mengejar strategi defender (Miles \& Snow, dalam Hult, Snow, dan Kandemir, 2003). Dari waktu ke waktu, organisasi mengembangkan orientasi terhadap entrepreneurship yang menyatu dengan budayanya. Beberapa organisasi menaruh perhatian entrepreneurship lebih dari yang lain, dan hal ini memengaruhi orientasi mereka terhadap faktor daya saing lainnya seperti innovativeness, customers dan markets, dan learning.

\section{Innovativeness}

Karena innovativeness memainkan peran penting dalam kesuksesan perusahaan dalam memperoleh keunggulan bersaing yang berkelanjutan, berbagai studi mencoba untuk mengungkapkan hubungan antara innovativeness dan kinerja (Lin, Peng and Kao 2008). Organisasi yang beroperasi dalam lingkungan dinamis mungkin lebih bermanfaat dalam inovasi produk baru dibandingkan perusahaan yang beroperasi dalam lingkungan yang stabil (Miller, 1983; Miller, 1988; Zahra, 1993 dalam Kreiser \& Davis 2010). Drucker dalam Lee \& Shieh (2010) mempertimbangkan inovasi karena memberikan sumber daya kemampuan baru untuk menciptakan kemakmuran. Inovasi, penemuan atau adopsi sesuatu yang baru atau berbeda, secara konsep sangat dekat dengan entrepreneurship atau penciptaan kombinasi baru sumber daya (Hult, Snow, dan Kandemir, 2003). 
Innovativeness menyiratkan perusahaan menjadi proaktif dengan menggali peluang baru bukan sekadar memanfaatkan kekuatan saat ini (Menguc \& Auh 2006). Oleh karenanya, perbedaan berikutnya dibuat oleh Zaltman, Duncan, dan Holbeck 1973 dalam Hult, Snow, dan Kandemir, 2003, memfokuskan studi pada innovativeness yang merupakan orientasi kultural organisasi (nilai dan keyakinan) terhadap inovasi. Innovativeness dapat dibedakan dari kapasitas berinovasi, yang merupakan kemampuan organisasi untuk berkembang secara sukses atau mengadopsi produk dan proses baru (Cohen \& Levinthal, dalam Hult, Snow, dan Kandemir, 2003). Innovativeness, jika dikombinasikan dengan faktor daya saing kultural dapat menciptakan kapasitas yang lebih besar untuk berinovasi yang sebaliknya mengakibatkan kinerja organisasional unggul (Hult, Snow, dan Kandemir, 2003). Untuk menjadi lebih spesifik, perusahaan yang berorientasi pada perubahan nilai inovasi dan mendorong pengambilan risiko dan kreativitas membuat karyawan merasa kurang terancam ketika mempertaruhkan upaya ke dalam bidang baru (Zhang \& Duan, 2010). Deshpande et al. dalam Hult (2001) juga menemukan bahwa innovativeness yang diwujudkan dalam budaya perusahaan memiliki dampak positif pada kinerja bisnis.

\section{Market Orientation}

Orientasi pasar merupakan prinsip dasar kultural organisasi belajar (Slater \& Narver dalam Hult, Snow, dan Kandemir, 2003). Salah satu dasar rumusan RBV adalah bahwa perusahaan yang bernilai, jarang, dan rumit secara sosial, serta yang sumber dayanya sulit ditiru menghasilkan keunggulan bersaing; dan dengan demikian, tingkat pengembalian di atas normal (Barney 1991; Wernerfelt 1984 dalam Menguc \& Auh 2006). Organisasi yang digerakkan pasar merupakan organisasi yang menempatkan prioritas tinggi dalam menciptakan nilai bagi konsumen yang ada dan potensial (Day, 1994 dalam Hult, Snow, dan Kandemir, 2003). Perusahaan dengan budaya berorientasi pasar mengembangkan kapabilitas dalam intelijen pasar dan strategi mereka responsif terhadap informasi yang dikumpulkan dari konsumen dan pihak berkepentingan eksternal lainnya. Perusahaan itu juga mengembangkan kemampuan untuk mengoordinasikan proses internal sehingga mereka dapat bertindak dengan cepat dan efektif (Day, 1994; Narver \& Slater, 1990 dalam Hult, Snow, dan Kandemir, 2003). Orientasi pasar yang kuat, jika bergabung dengan budaya yang menekankan entrepreneurship dan innovativeness, memunculkan organizational learning (Slater \& Narver, dalam Hult, Snow, dan Kandemir, 2003). Orientasi pasar juga telah dihubungan dengan keinovatifan. Seperti disarankan oleh Drucker dalam Ollavarieta dan Friedmann (1999), marketing dan inovasi adalah dua fungsi yang saling berhubungan untuk setiap bisnis.

Meskipun beberapa kerangka orientasi pasar yang layak ada (Deshpandé, Farley \& Webster, 1993; Kohli \& Jaworski, 1990 dalam Hult, Snow, dan Kandemir, 2003), kita mengadopsi konseptualisasi Narver dan Slater (1990) karena berfokus pada budaya organisasi. Dari arti penting tertentu dalam kerangka, mereka berpengaruh pada orientasi konsumen, pesaing, dan koordinasi antar fungsi. Dimensi orientasi pasar oleh karenanya menjadi bagian dari daya saing kultural organisasi (Hult, Snow, dan Kandemir, 2003). Slater dan Narver dalam Hult, Snow, dan Kandemir (2003) menyarankan bahwa orientasi pasar merupakan hal yang tak terpisahkan dengan organisasi belajar.

\section{Organizational Learning}

Pembelajaran organisasional dirumuskan sebagai proses penggunaan pengetahuan dan wawasan dengan tujuan untuk meningkatkan perilaku dan kinerja (Fiol \& Lyles, 1985; Huber, 1991; Simon, 1991 dalam Tran, 2008). Pengetahuan, diturunkan dari pembelajaran, secara potensial merupakan sumber daya yang paling produktif dalam organisasi dan dapat menjadi sumber daya keunggulan bersaing (Barney, 1991; Grant, 1996 dalam Hult, Snow, dan Kandemir, 2003). Persediaan pengetahuan organisasi diciptakan dan diperluas melalui proses pembelajaran (Daft \& Huber, 1987; Daft \& Weick, 1984 dalam Hult, Snow dan Kandemir, 2003). Proses pembelajaran yang efektif dalam organisasi melibatkan beberapa tahap utama. Setiap tahap harus dirancang dan dikelola secara hati- 
hati. Tahap-tahap itu adalah pemerolehan informasi, interpretasi, eksperimen yang terfokus, penyebaran pengalaman, dan restrukturisasi pengetahuan (Hanssen-Bauer \& Snow, 1996 dalam Hult, Snow, dan Kandemir, 2003).

Pembelajaran organisasional digambarkan sebagai pembelajaran ditempat kerja, yang merupakan gaya pembelajaran tingkat rendah melibatkan penggunaan pengetahuan yang ada untuk meningkatkan efisiensi operasi dalam perusahaan berskala kecil (Badger et al., 2001; Chaston et al., 2001 dalam Keskin, 2006). Pembelajaran organisasional merupakan kapabilitas yang memungkinkan perusahaan menciptakan pengetahuan sebagai sumber kinerja yang meningkat (Hitt \& Ireland, dalam Dess et al., 2003). Fokus studi pada nilai dan keyakinan bersamaan dengan pembelajaran organisasional. Dalam hal ini, perhatian kita pada bagaimana manajer memandang aspek tertentu dalam proses pembelajaran seperti nilai tim kerja lintas fungsi, antar-keterhubungan berbagai bagian dalam organisasi dan apakah ada mekanisme untuk berbagi pengetahuan dan pengalaman (Hult, Snow, dan Kandemir, 2003). Pembelajaran organisasional bernilai bagi konsumen perusahaan karena memfokuskan pada pemahaman dan secara efektif memuaskan ungkapan mereka dan kebutuhan yang tersembunyi melalui produk, layanan, dan cara-cara baru dalam melakukan bisnis (Slater \& Narver, 1995; Lukas et al., 1996 dalam Lopez et al., 2005).

\section{Konsep Intrapreneurship}

Dalam organisasi yang sudah mapan, dimungkinkan bahwa untuk menjadi entrepreneurial memerlukan kapabilitas dinamis yang ditanamkan dalam rutinitas organisasional yang memungkinkan perusahaan secara kontinu mencari, mengenal, dan memanfaatkan peluang baru (Zahra, 2008). Istilah-istilah seperti intrapreneuring (Pinchot, dalam Antoncic \& Hisrich, 2001), corporate entrepreneurship (Burgelman 1983; Vesper 1984; Guth and Ginsberg 1990; Hornsby et al., 1993; Stopford \& Baden-Fuller, 1994, dalam Antoncic \& Hisrich 2001), corporate venturing (MacMillan 1986; Vesper 1990 dalam Antoncic \& Hisrich 2001), dan internal corporate entrepreneurship (Schollhammer 1981, 1982; Jones \& Butler, 1992; dalam Antoncic \& Hisrich, 2001) telah digunakan untuk menjelaskan fenomena intrapreneurship.

Konsensus yang meningkat telah diperoleh pada konsep entrepreneurship sebagai proses pengungkapan dan pengembangan peluang untuk menciptakan nilai melalui inovasi dan perebutan peluang tanpa menganggap sumber daya (manusia dan kapital) atau lokasi entrepreneur dalam perusahaan baru atau yang sudah ada (Churchill, dalam Antoncic \& Hisrich 2001). Mungkin definisi yang lebih luas intrapreneurship adalah entrepreneurship dalam organisasi saat ini.

Dalam riset sebelumnya, intrapreneurship dipandang sebagai proses dimana individu dalam organisasi mengejar peluang tanpa menganggap sumber daya yang mereka kendalikan saat ini (Stevenson \& Jarillo, dalam Antoncic \& Hisrich 2001) sebagai sesuatu yang baru dan datang dari kebiasaan untuk mengejar peluang (Vesper, dalam Antoncic \& Hisrich, 2001), dan sebagai semangat entrepreneurship dalam organisasi saat ini (Hisrich \& Peters, dalam Antoncic \& Hisrich, 2001). Beberapa peneliti menggunakan definisi yang lebih sempit mengecualikan organisasi yang lebih kecil dan berfokus pada perusahaan (Schollhammer, 1982; Burgelman, 1983, 1985; Pinchot 1985; Rule \& Irwin 1988; Kuratko et al., 1993; dalam Antoncic \& Hisrich, 2001). Peneliti yang lain membatasi mereka sendiri hanya pada pembentukan venture/usaha baru (Kanter \& Richardson, 1991; Baduerahanian \& Abetti 1995 dalam Hult, Snow, dan Kandemir, 2003). Dalam studi ini intrapreneurship dirumuskan sebagai entrepreneurship dalam organisasi saat ini. Hal ini mengacu pada proses yang berjalan dalam perusahaan yang ada saat ini, tanpa menganggap ukuran, dan bukan hanya usaha bisnis baru, tetapi juga kegiatan dan orientasi inovatif lainnya seperti pengembangan produk, jasa, teknologi, teknik administratif, strategi, dan sikap kompetitif (Antoncic \& Hisrich 2001). 


\section{Dimensi Intrapreneurship}

Pandangan sebelumnya tentang intrapreneurship dapat digolongkan dalam empat dimensi: new business venturing, innovativeness, self-renewal, dan proactiveness. New business venturing merupakan karakteristik intrapreneurship yang paling menonjol karena dapat menghasilkan penciptaan usaha baru dalam organisasi yang ada saat ini (Stopford \& Baden-Fuller, dalam Antoncic \& Hisrich, 2001) dengan merumuskan kembali produk atau jasa perusahaan (Rule \& Irwin 1988; Zahra, 1991 dalam Antoncic \& Hisrich, 2001) dan/atau dengan pengembangan pasar baru (Zahra, 1991). Dalam korporasi yang besar dapat juga dimasukkan pembentukan unit atau perusahaan otonomi atau semiotonomi secara lebih formal (sering disebut entrepreneurship inkubatif) (Schollhammer, 1981; 1982, dalam Antoncic \& Hisrich, 2001), internal venturing (Hisrich \& Peters, dalam Antoncic \& Hisrich, 2001), corporate start-ups (MacMillan et al., 1984, dalam Antoncic \& Hisrich, 2001), penciptaan unit bisnis otonomi (Vesper, 1984, dalam Antoncic \& Hisrich, 2001) dan newstreams (Kanter \& Richardson, dalam Antoncic \& Hisrich, 2001). Bagi semua organisasi, tanpa menganggap ukuran, dimensi new business-venturing menawarkan penciptaan bisnis baru dalam organisasi yang ada saat ini tanpa menganggap tingkat otonomi (Antoncic \& Hisrich, 2001).

Sebaliknya, dimensi innovativeness mengacu pada inovasi produk dan jasa dengan menekankan pada pengembangan dan inovasi dalam teknologi. Intrapreneurship meliputi pengembangan produk baru, perbaikan produk serta metode, dan prosedur produksi baru (Schollhammer, 1982; dalam Antoncic \& Hisrich, 2001). Covin dan Slevin (1991, dalam Antoncic \& Hisrich, 2001) mempertimbangkan satu bagian dari postur entrepreneurial yang menggambarkan dirinya sendiri dalam keluasan dan frekuensi inovasi produk dan kecenderungan yang berhubungan dengan kepemimpinan teknologi. Knight (1997) memasukkan pengembangan dan peningkatan produk, jasa dan teknik dan teknologi dalam produksi sebagai bagian keinovatifan organisasional. Zahra (1993, dalam Antoncic \& Hisrich, 2001) memasukkan inovasi produk dan entrepreneurship teknologi sebagai aspek inovatif dalam perusahaan manufaktur.

Dimensi self-renewal menggambarkan transformasi organisasi melalui pembaruan ide utama yang mereka bangun (Guth \& Ginsberg, 1990; Zahra, 1991, dalam Antoncic \& Hisrich, 2001). Hal ini memiliki konotasi perubahan strategis dan organisasional; dan meliputi redefinisi konsep bisnis, reorganisasi, dan pengenalan perubahan tingkat-sistem untuk inovasi (Zahra, 1993, dalam Antoncic \& Hisrich, 2001). Vesper (1984, dalam Antoncic \& Hisrich, 2001) memandang arah strategis baru (penyimpangan yang signifikan dari strategi korporat) sebagai bagian dari intrapreneurship. Muzyka et al. (1995, dalam Antoncic \& Hisrich, 2001) mempertimbangkan sangat penting organisasional untuk secara kontinu memperbarui bisnisnya dan mencapai penyesuaian dan fleksibilitas sebagai karakteristik krusial perusahaan yang entrepreneurial. Stopford dan Baden-Fuller (1994, dalam Antoncic \& Hisrich, 2001) memandang aktivitas yang bersamaan dengan pembaruan dalam organisasi yang ada saat ini sebagai elemen intrapreneurship.

Dimensi terakhir-proactiveness-berhubungan dengan sikap yang agresif relatif bagi pesaing (Knight, 1997). Perusahaan yang proaktif cenderung mengambil risiko dengan melakukan ekperimen (Stopford \& Baden-Fuller, 1994 dalam Antoncic \& Hisrich, 2001). Perusahaan mengambil inisiatif (Lumpkin \& Dess, 1996 dalam Antoncic \& Hisrich, 2001) dan berani serta agresif dalam mengejar peluang (Covin \& Slevin, dalam Antoncic \& Hisrich, 2001). Konsep proactiveness mengacu pada sampai sejauh mana organisasi mencoba untuk memimpin bukan sekadar mengikuti pesaing bidang bisnis utama sebagai pengenalan produk baru atau jasa, teknologi operasi dan teknik administratif (Covin \& Slevin, dalam Antoncic \& Hisrich, 2001). Covin \& Slevin dalam Antoncic \& Hisrich (2001) merasa bahwa hal ini digambarkan dalam kecenderungan perusahaan secara agresif dan proaktif bersaing dengan musuh industri. Stopford \& Baden-Fuller's (dalam Antoncic \& Hisrich, 2001), jenis perubahan frame-breaking dan Miller’s (dalam Antoncic \& Hisrich, 2001) pembuatan strategi yang tegas adalah sebangun dengan dimensi ini. Mintzberg (dalam Antoncic \& Hisrich, 2001) 
melihat pengambilan risiko dan tindakan yang menentukan, yang terkatalisasi oleh pemimpin kuat sebagai elemen model entrepreneurial. Miles dan Snow (dalam Antoncic \& Hisrich, 2001) merasa bahwa strategi entrepreneurial terdiri atas berani/tegas, penuh arah, gaya mencari peluang dengan aspek pengambilan risiko, dan ekperimental. Proactiveness meliputi inisiatif dan pengambilan risiko, dan keagresifan serta ketegasan kompetitif yang digambarkan dalam orientasi dan aktivitas top manajemen (Antoncic \& Hisrich 2001).

\section{METODE}

Data dihasilkan dari survei primer (interview dan mail survey) ke seluruh lembaga perguruan tinggi (negeri dan swasta) yang diambil sebagai sampel dari direktori perguruan tinggi. Metode sampling dalam riset ini menggunakan stratified-proportional sampling. Kurang lebih 500 kuesioner akan dikirim karena jumlah ini menjangkau lebih dari $10 \%$ dari jumlah perguruan tinggi yang ada di Indonesia (2963) dan karena homogenitas dari sampel dan kemungkinan terjadinya kuesioner yang tidak terjawab. Karena memiliki lebih dari dua variabel, dalam riset multivariat, Sekaran (2010) menyarankan bahwa ukuran sampel seharusnya sepuluh kali lebih dibandingkan jumlah variabel dalam studi ini. Jumlah dari sampel yang digunakan (500) akan mencukupi batas dari bias. Ukuran sampel lebih dari 30 dan kurang dari 500 tepat untuk kebanyakan riset saat ini (Sekaran, 2010). Pengumpulan data awal juga akan dilakukan untuk menguji construct yang digunakan dan untuk meningkatkan keakuratan.

SEM (Structural Equation Modeling) via LISREL akan digunakan untuk menguji setiap model dalam jenis organisasi yang berbeda termasuk validitas dan reliabilitas. SEM digunakan karena memungkinkan kita untuk menguji serangkaian hubungan bebas secara simultan (Hult, Snow, dan Kandemir, 2010).

\section{Pengembangan Model Penelitian}

Peneliti berbagai disiplin saat ini telah melakukan berbagai diskusi tentang orientasi pasar, inovasi, organisasi belajar, dan entrepeneurship. Uraian singkat model dari empat komponen berbasis budaya: (1) orientasi pasar akan digunakan dengan mengadopsi konseptualisasi dari Narver dan Slater (1990). Orientasi pasar terdiri dari: customer orientation, competitor orientation dan inter-functional coordination; (2) innovativeness, komponen ini memfokuskan pada innovativeness sebagai orientasi kultural organisasi terhadap nilai dan keyakinan yang mengarahkan pada inovatif (Hult, Snow, dan Kandemir, 2003); (3) organizational learning, komponen ini merupakan pandangan manajer pada dimensi proses pembelajaran seperti orientasi team, system, learning, dan memory (Hult, Snow, dan Kandemir, 2003); (4) intrapreneurship, komponen ini mencakup new business venturing, innovativeness, self-renewal, dan proactiveness (Antonic \& Hisrich, 2001); (5) organization performance, ada karakteristik multidimensi terhadap kinerja organisasi (Pelham, 1999). Sebagai contoh: marketing/sales effectiveness (relative product quality, new product success, and customer retention), growth/share (level of sales revenue, sales growth, and target market share) dan profitability (return on equity, return on investment, and gross profit margin).

Alternatif model yang diuji oleh Hult, Snow, dan Kandemir (2003) di USA akan digunakan pada sektor jasa yaitu Perguruan Tinggi di Indonesia. Model yang akan diuji adalah seperti pada Tabel 1 . 
Tabel 1 Model yang diuji pada perguruan tinggi

Model 1 Entrepreneurship, innovativeness, organizational learning dan market orientation dimodelkan sebagai indikator urutan pertama dari urutan yang lebih tinggi faktor keunggulan posisi yang mempengaruhi performance. Model ini didasarkan pada riset oleh Hult \& Ketchen (2001) dan Hult et al., (2002).

Model 2 Entrepreneurship, innovativeness, organizational learning, dan market orientation dimodelkan sebagai faktor yang memiliki pengaruh langsung pada performance. Model ini dikembangkan oleh Hult \& Ketchen (2001) dan Hult et al., (2002).

Model 3 Market orientation dimodelkan untuk memengaruhi innovativeness, organizational learning, dan entrepreneurship. Learning memengaruhi innovativeness dan entrepreneurship, yang kemudian secara bersama-sama memengaruhi performance (Webster, 1992).

Model 4 Entrepreneurship, innovativeness, dan market orientation dimodelkan untuk memengaruhi organizational learning secara langsung dan sebaliknya memengaruhi performance. Model ini diadopsi dari Slater \& Narver (1995) yang mengembangkan modelnya berdasarkan literatur organizational learning (e.g., Huber, 1991).

Model 5 Entrepreneurship, market orientation, dan innovativeness dimodelkan untuk memengaruhi organizational learning secara langsung. Entrepreneurship, innovativeness, dan organizational learning memiliki pengaruh langsung pada performance. Model ini menggambarkan versi terbaru riset oleh Slater \& Narver $(1998,1999)$.

Model 6 Innovativeness, market orientation dan organizational learning dimodelkan untuk memengaruhi entrepreneurship secara langsung dan sebaliknya mempengaruhi performance. Model ini dimotivasi dari sebagian besar literatur entrepreneurship (e.g., Lumpkin \& Dess, 1996; Naman \& Slevin, 1993).

Model 7 Entrepreneurship, market orientation, dan organizational learning dimodelkan untuk memengaruhi innovativeness secara langsung dan sebaliknya memengaruhi performance, Model ini dimotivasi dari literatur innovation (e.g., Daft, 1982; Damanpour, 1991; Han, Kim \& Srivastava, 1998).

Model 8 Entrepreneurship, innovativeness, dan organizational learning dimodelkan untuk memengaruhi market orientation secara langsung dan sebaliknya memengaruhi performance. Model ini dimotivasi dari literatur market-driven organization (e.g., Despande \& Farley, 1998; Jaworski \& Kohli, 1996).

Model 9 Organizational learning memengaruhi secara langsung dan sebaliknya memengaruhi entrepreneurship dan innovativeness. Innovativenes dimodelkan untuk memengaruhi entrepreneurship, kemudian innovativeness dan entrepreneurship memengaruhi performance. Model ini didasarkan pada sebagian besar riset (e.g., Baker \& Sinkula, 1999; Hurley \& Hult, 1998; Lumpkin \& Dess, 1996; Naman \& Slevin, 1993; Sinkula, Baker \& Noordewier, 1997).

Model $10 \quad$ Model yang berurutan: organizational learning $\rightarrow$ market $\rightarrow$ orientation $\rightarrow$ innovativeness $\rightarrow$ entrepreneurship $\rightarrow$ performance, dimotivasi dari serangkaian pekerjaan independen seperti Christensen \& Bower (1996), Han et al., (1998), Huber (1991), Jaworski \& Kohli (1996), Lumpkin \& Dess (1996), and Naman \& Slevin (1993). 
Sepuluh model yang akan diuji dalam riset ini menggunakan model yang dikembangkan oleh Hult, Snow, dan Kandemir (2003) seperti pada Gambar 1.

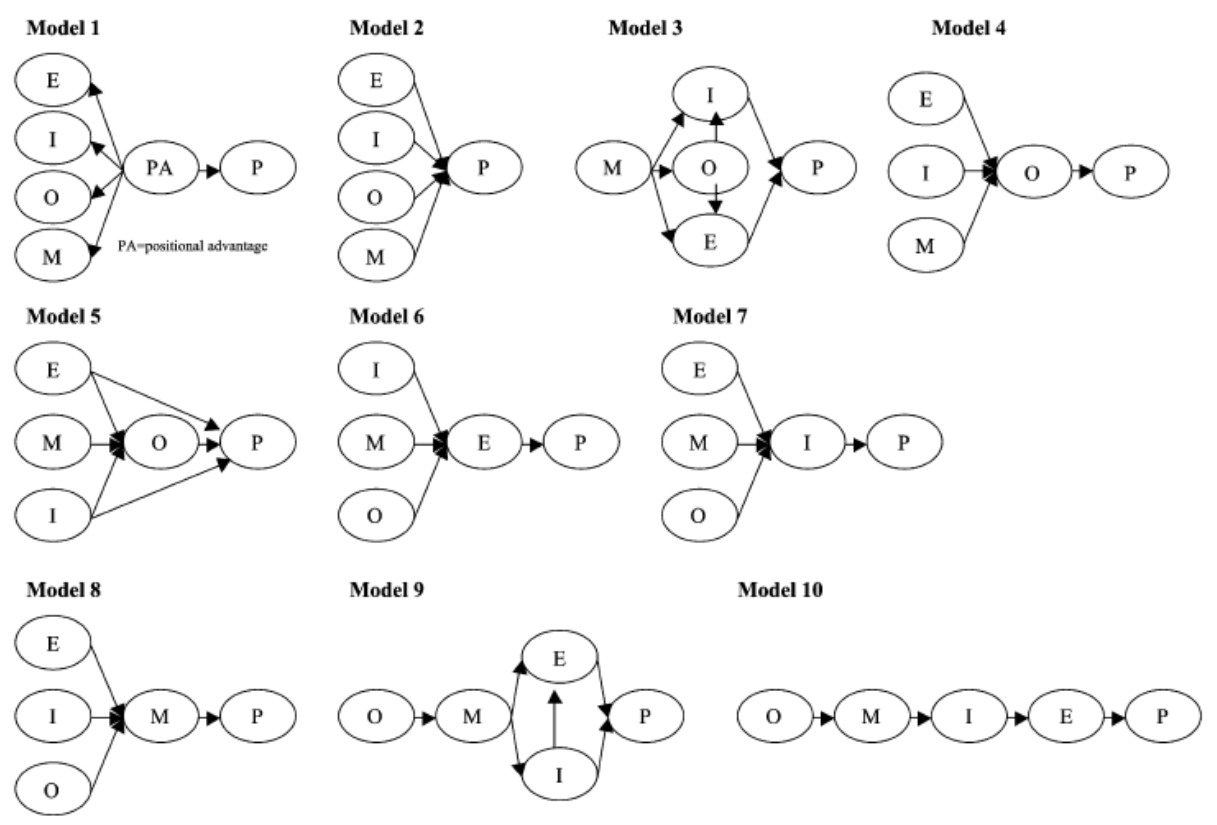

Gambar 1 Pengembangan model penelitian

\section{Keterangan:}

$\mathrm{E}=$ Entrepreneurship $\quad \mathrm{I}=$ Innovativeness $\quad \mathrm{O}=$ Organizational Learning

$\mathrm{M}=$ Market Orientation $\mathrm{P}=$ Performance $\mathrm{PA}=$ Positional Advantage

\section{Aplikasi Model}

Pengembangan model ini akan diterapkan pada penelitian dengan confirmatory yang akan menguji sepuluh alternatif model analitis yang dikembangkan oleh Hult, Snow, dan Kandemir (2003) di Amerika Serikat. Setiap model akan diuji dalam sampel menyeluruh (full sample) dan tersegmentasi (segmented sample) pada lembaga perguruan tinggi di Indonesia (negeri/besar, negeri/kecil, swasta/besar, swasta/kecil). Hubungan sebab-akibat akan diukur sesuai model dan jenis organisasi. Model ini akan menentukan posisi variabel yang dianggap sebagai independent/dependent/intervening.

Lima variabel yang terlibat, terdiri dari market orientation, innovativeness, learning organization, intrapreneurship, dan organization performance. Karena terbatasnya ketersediaan dan keterjangkauan data, akan digunakan perceptual judgment untuk menghasilkan penilaian kinerja yang objektif. Studi menunjukkan bahwa ada validitas dalam perceptual judgment dimana korelasi tinggi ditemukan antara indikator objektif dan persepsi (Dess \& Robinson, 1984; Venkatraman \& Ramanujam, 1986 dalam Morgan \& Strong, 2003).

Untuk mengukur market orientation, akan didasarkan pada konsep orientasi pasar dari Narver dan Slater (1990): customer orientation, competitor orientation, and inter-functional coordination karena difokuskan pada organizational culture. Untuk mengukur organizational learning, akan didasarkan pada dimensi learning process seperti team, systems, learning, dan memory orientation (Hult, 1998; Hult, Snow, dan Kandemir, 2000; dalam Hult, Snow, dan Kandemir, 2003). 
Untuk mengukur intrapreneurship, akan digunakan apa yang telah dikembangkan oleh Khandwalla (dalam Knight, 1997), yang mengembangkan delapan butir untuk mengukur intrapreneurship (enterscale). Meskipun demikian, skala ini hanya mengukur innovation dan proactiveness. Skala kedua akan menggunakan "the corporate entrepreneurship scale", yang dikembangkan dan diperbaiki oleh Zahra (1991, 1993) dalam Hult, Snow, dan Kandemir (2003), yang terdiri dari aktivitas corporate entrepreneurship seperti venturing innovation, dan self-renewal.

Untuk mengukur innovativeness, riset ini akan menggunakan pengukuran sebelumnya yang digunakan oleh Hurley dan Hult (1998), Hult dan Ketchen (2001) dalam Hult, Snow, dan Kandemir (2003). Untuk mengukur performance, akan didasarkan pada apa yang digunakan oleh Gupta \& Govindarajan (1984) dan Covin \& Slevin (dalam Pelham, 1999), yang menilai responden tentang kepuasan dengan kinerja organisasi pada setiap pengukuran (dibandingkan dengan pesaing) selama tiga tahun terakhir. Karena ketidakpraktisan dalam pengukuran yang objektif di lembaga perguruan tinggi, riset ini akan menggunakan pengukuran kinerja yang subjektif (perceptual measures).

Penelitian ini akan menggunakan skala Likert (Likert-type scale) dari pernyataan "sangat tidak setuju” sampai "sangat setuju” untuk mengukur dimensi cultural competitiveness (market orientation, innovativeness, organizational learning, dan intrapreneurship) dan organization performance (data ordinal).

Market orientation, innovativeness, organizational learning, dan intrapreneurship, merupakan fungsi yang sangat penting bagi tingkatan perusahaan. Riset ini akan memfokuskan pada firm-level business dengan unit ekonomi yang tidak terdiversikasi dan/atau tingkat bisnis unit. Unit bisnis strategis (SBU) dipilih sebagai unit analisis karena memungkinkan kita menganalisis jenis organisasi yang berbeda dengan menggunakan data daya saing kultural yang diperoleh dari manajer/eksekutif senior. Unit analisis SBU bermanfaat karena semua SBU dalam perusahaan tidak mungkin mengembangkan daya saing kultural dengan tujuan yang sama (Hult, Snow, dan Kandemir, 2003).

\section{Implikasi yang diharapkan}

Pengembangan model ini diharapkan akan memiliki beberapa implikasi manajerial, yaitu: (1) sepuluh model alternatif analitis dan butir-butir yang digunakan dalam riset (market orientation, innovativeness, organizational learning, dan intrapreneurship) dapat digunakan oleh pengelola perguruan tinggi sebagai dasar untuk meningkatkan daya saing kultural; (2) dapat diyakini bahwa organisasi dengan orientasi intrapreneurial lebih cepat tumbuh dibandingkan organisasi yang tidak berorientasi pada intrapreneurial. Jika riset ini dapat memberikan bukti bahwa intrapreneurship menyumbangkan pertumbuhan yang lebih baik dalam ekonomi transisi, pengelola perguruan tinggi dapat merancang kembali praktik bisnis dengan lebih mendorong tindakan intrepreneurial; (3) tingkatan dari empat komponen berbasis pasar yang lebih tinggi seharusnya memungkinkan perusahaan berada pada posisi yang kompetitif untuk tingkat kinerja yang lebih tinggi. Sehingga, organisasi dapat lebih proaktif dalam mengatur strategi dan perencanaan, lebih mengambil resiko dalam mengimplementasikan rencana, lebih mencari peluang untuk meningkatkan basis pengetahuan, dan lebih inovatif dalam menyampaikan produk dan jasa yang menguntungkan; (4) dampak interaktif dari empat komponen berbasis pasar mungkin berbeda dari ukuran dan status organisasi (perguruan tinggi). Sehingga, kesesuaian antara construct daya saing kultural tertentu dan jenis organisasi yang spesifik akan berfungsi sebagai pedoman bagi pengelola perguruan tinggi untuk menciptakan keunggulan bersaing. 


\section{PENUTUP}

Artikel ini membahas tentang pengembangan kerangka konseptual untuk menguji hubungan antara daya saing kultural dan kinerja perguruan tinggi. Intrapreneurship dinilai memiliki peran dan mampu memberikan kontribusi dalam meningkatkan kinerja di perguruan tinggi. Oleh sebab itu, perlu dikembangkan suatu model yang bisa menggantikan peran entrepreneurship dalam dimensi daya saing kultural. Langkah berikutnya adalah menguji kesepuluh model dengan tujuan untuk menemukan hasil yang diharapkan sebelum generalisasi dapat dibuat.

\section{DAFTAR PUSTAKA}

Antoncic, B., \& Hisrich, R. D. (2001). Intrapreneurship: construct refinement and cross-cultural validation. Journal of Business Venturing, 16: 495-527.

Dess, G. G., Ireland, R. D., Zahra, S. A., Floyd, S. W., Janney, J. J., \& Lane, P. J. (2003). Emerging issues in corporate entrepreneurship. Journal of Management, Vol. 29 No. 3 pp. 351-378.

Hult, G. T. M. (2001). Cultural competitiveness in global sourcing. Industrial Marketing Management, Vol. 31, 25-34.

Hult, G. T. M., Snow, C. C., \& Kandemir, D. (2003). The role of entrepreneurship in building cultural competitiveness in different organizational types. Journal of Management, 29 (3): 401-426.

Hult, G.T.M., \& Hurley, R. F. (1998). Innovation, market orientation, and organizational learning: an integration and empirical examination. Journal of Marketing, Vol. 62, 42-54.

Hult, G.T.M., Ketchen J. R., David, J., Nicholis, J. R., \& Ernest, L. (2002). An examination of cultural competitiveness and order fulfillment cycle time within supply chains. Academy of Management Journal, Vol. 45. No. 3, 577-586.

Keskin, H. (2006). Market orientation, learning orientation and innovation capabilities in SMEs, European Journal of Innovation Management, Vol. 9 No. 4, pp. 396-417.

Knight, G. A. (1997). Cross-cultural reliability and validity of a scale to measure firm entrepreneurial orientation. Journal of Business Venturing, 12: 213-225.

Kreiser, P. M., \& Davis, J. (2010). Entrepreneurial Orientation and Firm Performance: The Unique Impact of Innovativeness, Proactiveness, and Risk-taking. Journal of Small Business and Entrepreneurship, 23, no. 1: pp. 39-51.

Lopez, S. P., Peon, J. M. M., \& Ordas, C. J. V. (2005). Organizational learning as a determining factors in business performance. The Learning Organization, Vol. 12, No. 3 pp. 227-245.

Menguc, B., \& Auh, S. (2006). Creating a Firm-Level Dynamic Capability through Capitalizing on Market Orientation and Innovativeness. Academy of Marketing Science Journal, Vol. 34, No. 1, pp. 63-73.

Morgan, R.E., \& Strong, C. A. (2003). Business performance and dimensions of strategic orientation. Journal of Business Research, 56: 163-176. 
Narver, J. C., \& Slater, S. F. (1995). Market orientation and the learning organization. Journal of Marketing, Vol 59, 63-74.

Narver, J. C., and Slater, S. F. (1990). The effect of a market orientation on business profitability. Journal of Marketing, 54: 20-35.

Pelham, A. M. (1999). Influence of Environment, strategy, and market orientation on performance in small manufacturing firms. Journal of Business Research, 45: 33-46.

Sekaran, U. (2010). Research methods for business: A skill-building approach. New York: John Wiley \& Sons.

Tran, T. (2008). A conceptual model of learning culture and innovation schema. Competitiveness Review: an International Business Journal, Vol. 18, No. 3 pp. 287-299.

Zahra, A. S. (2008). Being entrepreneurial and market driven: implications for company performance. Journal of Strategic and Management, Vol. I No. 2 pp. 125-142. 